\title{
Flower-like tungsten oxide particles: Synthesis, characterization and dimethyl methylphosphonate sensing properties
}

\author{
Yingqiang Zhao ${ }^{\mathrm{a}, \mathrm{b}}$, Hongmin Chen ${ }^{\mathrm{a}}$, Xiaoying Wang ${ }^{\mathrm{c}}$, Junhui $\mathrm{He}^{\mathrm{a}, *}$, Yunbo $\mathrm{Yu}^{\mathrm{c}}, \mathrm{Hong} \mathrm{He}^{\mathrm{c}}$ \\ a Functional Nanomaterials Laboratory and Key Laboratory of Photochemical Conversion and Optoelectronic Materials, Technical Institute of Physics and Chemistry, \\ Chinese Academy of Sciences, Zhongguancun Beiyitiao 2, Haidianqu, Beijing 100190, China \\ ${ }^{\mathrm{b}}$ Graduate University of Chinese Academy of Sciences, Beijing 100049, China \\ ${ }^{\mathrm{c}}$ Research Center for Eco-Environmental Sciences, Chinese Academy of Sciences, Beijing 100085, China
}

\section{A R T I C L E I N F O}

\section{Article history:}

Received 11 May 2010

Received in revised form 23 June 2010

Accepted 24 June 2010

Available online 1 July 2010

\section{Keywords:}

Flower-like

Tungsten oxide

Quartz crystal microbalance

Gas sensor

Dimethyl methylphosphonate

\begin{abstract}
A B S T R A C T
Flower-like $\mathrm{WO}_{3}$ particles with high specific surface area were synthesized via a template/surfactantfree way. Scanning and transmission microscopies and X-ray diffraction were applied to investigate the formation mechanism of the morphology. Gas sensing characterization showed an enhanced sensitivity $(70 \mathrm{~Hz} / \mathrm{ppm})$ to dimethyl methylphosphonate (DMMP) as compared with previously reported $\mathrm{WO}_{3}$ nanoflakes $(38 \mathrm{~Hz} / \mathrm{ppm}$ ) at a DMMP concentration of $4 \mathrm{ppm}$. Cross-sensitivity results revealed that flower-like $\mathrm{WO}_{3}$ still showed sound sensitivity in presence of interfering agents, which benefited from its intrinsic high sensitivity. The mechanism of DMMP adsorption on the flower-like $\mathrm{WO}_{3}$ particle was studied by in situ diffuse reflectance infrared Fourier transform spectroscopy.
\end{abstract}

(c) 2010 Elsevier B.V. All rights reserved.

\section{Introduction}

Syntheses of inorganic materials with controlled morphologies, sizes, and architectures have attracted intensive interests since these parameters play a key role in determining their electrical, optical and sensing properties [1-3]. An ideal sensor requires high sensitivity, short response and recovery time as well as high selectivity. To satisfy these requirements, it is important to choose an appropriate material with appropriate morphology, size and architecture.

The G-series of nerve agents including Sarin, Soman and Tabun are inhibitors of serine proteases, and their primary toxicity results from the inhibition of acetylcholinesterase [4]. Some methods such as luminescence [5-7], electrochemistry [8] for detection of these nerve agents have been described in recent reports. However, these methods are usually limited by low sensitivity, operational complexity and non-portability. Since hydrogen-bond acidic polymers were discovered to have high sensitivity to organo-phosphorus nerve agents by using acoustic wave sensors in the mid 1980s [9], mass sensors for nerve agents detection have attracted much attention. Of all kinds of mass sensors, Quartz crystal microbalance (QCM)-based mass sensors are most attractive as they have advan-

\footnotetext{
* Corresponding author. Tel.: +86 10 82543535; fax: +861082543535

E-mail address: jhhe@mail.ipc.ac.cn (J. He).
}

tages of low cost, low energy consumption, high sensitivity, fast response and easy fabrication.

Traditional sensing films used in QCM sensors to detect nerve agents are hydrogen-bond acidic polymers. These polymers are also applied as adsorbent on sample collectors and preconcentrators $[10,11]$. Despite their high sensitivity, the applications of these materials have been limited by their poor stability and relative long response and recovery time. The fast development of synthesis methods for nanomaterials have provided metal oxides with various morphologies and high specific surface areas, thus making it possible to adopt acidic metal oxides as sensing material to detect nerve agents. Compared with hydrogen-bond acidic polymers, acidic metal oxides are doubtlessly steadier. Furthermore, oxides with controlled morphologies may have shorter response, recovery time and even higher sensitivity than polymers.

Surfactant-assisted wet-chemical routes $[12,13]$ are considered a good way to fabricate nano-sized metal oxides with high specific surface areas. However, calcination, which is mostly applied for removal of surfactant, often destroys the surface structure of product especially when abundant adsorbed water exists. Our previous work [14] indicated that strongly adsorbed water can affect the sensing characteristics of the material. In the current work, we have successfully prepared flower-like tungsten oxide particles with high specific surface area in a facile surfactant-free way, and used them as sensing layer to detect dimethyl methylphosphonate (DMMP), a simulant for nerve agents. A comparative study with previous $\mathrm{WO}_{3}$ nanoflakes was also conducted in order to examine 
the effects of morphology and specific surface area on the sensing characteristics. The possible sensing mechanism will be also discussed in detail.

\section{Experimental}

\subsection{Materials syntheses}

Flower-like tungsten oxide was synthesized in a facile solvothermal method. Typically, $3 \mathrm{~g} \mathrm{WCl}_{6}$ (ca. $7.5 \mathrm{mmol}$ ) was dispersed in $80 \mathrm{~mL}$ ethanol, and a pale yellow solution was obtained after 5 min constant stirring. Then the solution was transferred into a $100 \mathrm{~mL}$ autoclave, which was put into an electrothermic oven, and heated to $100^{\circ} \mathrm{C}$ from room temperature. After reaction at this temperature for $72 \mathrm{~h}$, a blue precipitate was collected and washed several times with ethanol. The final product was dried at $80^{\circ} \mathrm{C}$ in vacuum.

\subsection{Sensor fabrication}

A drop-coating method was applied to coat both sides of a silvercoated ( $5 \mathrm{~mm}$ in diameter) piezoelectric quartz crystal (AT-cut, $9 \mathrm{MHz}$ ) with a sensing material. In a typical procedure, the obtained product was dispersed in water, and the obtained suspension was dropped onto the surface of silver electrode using a microsyringe. The QCM resonators with thin films were quickly dried at $30^{\circ} \mathrm{C}$ in vacuum. Although it is a simple method, it was proved both effective and satisfactory for the aim of the current work [14].

\subsection{Instrumentation}

Functionalized QCM resonators were tested in a glass chamber which was put in an incubator where a controlled temperature was provided. A dynamic gas-mixing apparatus was used to steadily generate gas containing DMMP of low concentration. Vapor generated by liquid DMMP was taken away by a mass flow controller manipulated gas flow, and then was further diluted in proportion by another steady gas flow. In order to simulate the real environment and keep all environmental conditions consistent, all gas flows were dry air provided by an air compressor through desiccating columns. The relative humidity of dry air was strictly controlled at $5 \%$. A four-way valve was applied to switch between dry air flow and diluted DMMP flow. Frequency shifts were recorded by an Agilent 53131A universal counter linked to a computer.

Cross-sensitivity tests were conducted in presence of interfering agents under otherwise identical conditions. Vapors of interfering agents were generated by placing liquid interfering agents at the bottom of the chamber. Measured frequency shifts were normalized by 10,000 ppm of interfering agents.

In situ diffuse reflectance infrared Fourier transform spectroscopy (DRIFTS) was performed on a Nexus 670 (Thermo Nicolet) FT-IR spectrometer equipped with an in situ diffuse reflection chamber and a high-sensitivity MCT detector. Materials for in situ DRIFTS studies were placed in a ceramic crucible in the in situ chamber. Mass flow controllers were used to control flow rates, which were identical to the gas sensing tests. Prior to recording each DRIFTS spectrum, the materials were pretreated with $\mathrm{N}_{2}$ at $80^{\circ} \mathrm{C}$ for $1 \mathrm{~h}$, and then cooled to room temperature. After acquiring a reference spectrum, a flow of $500 \mathrm{~mL} / \mathrm{min} \mathrm{N}_{2}$ was introduced into a gas-mixing apparatus to carry away DMMP vapor, and the mixed gas was let into the in situ diffuse reflection chamber. A series of DMMP adsorption spectra were collected with time. The spectrum collection lasted for $30 \mathrm{~min}$. All spectra reported here were collected at a resolution of $4 \mathrm{~cm}^{-1}$ for 100 scans.

$\mathrm{X}$-ray diffraction (XRD) patterns of as-prepared $\mathrm{WO}_{3}$ were recorded on a Holand PANalytical X'Pert PRO MPD X-ray diffrac- tometer using $\mathrm{Cu} \mathrm{K} \alpha$ radiation $(\lambda=0.1542 \mathrm{~nm})$ operated at $40 \mathrm{kV}$ and $40 \mathrm{~mA}$. SEM observations were carried out on a Hitachi S-4300 field emission scanning electron microscope. Transmission electron microscopy (TEM) and high-resolution TEM (HRTEM) images were obtained on a JEOL 2100 transmission electron microscope at an acceleration voltage of $200 \mathrm{kV}$.

A Quantasorb-18 automatic equipment (Quanta Chrome Instrument Co.) was applied to determine surface area and pore volume by nitrogen adsorption-desorption isotherms at $-196^{\circ} \mathrm{C}$ over the whole range of relative pressures.

\section{Results and discussion}

\subsection{Morphology and microstructure of as-prepared $\mathrm{WO}_{3}$}

Fig. 1a shows the overall morphology of as-prepared $\mathrm{WO}_{3}$. Clearly, it has a flower-like morphology which consists of a large number of nanoflakes. The flake thickness is ca. $20 \mathrm{~nm}$, as estimated from enlarged SEM image (Fig. 1b). To further investigate the structure of the $\mathrm{WO}_{3}$ particles, HRTEM images were collected and are shown in Fig. 1c and d. Fig. 1c shows that the $\mathrm{WO}_{3}$ particle consists of nanoflakes. Fig. 1d is a HRTEM image of a nanoflake fragment which shows clear lattice fringes. The $d$ spacings of the lattice fringes are 0.376 and $0.364 \mathrm{~nm}$, respectively, corresponding to the $(020)$ and $(200)$ planes of monoclinic $\mathrm{WO}_{3}$.

Acidic metal oxides have abundant Lewis and Brønsted sites, where adsorption and/or catalysis may take place $[15,16]$. As the amount of water on the surface of metal oxides can alter the number of those acid sites, a TG analysis was applied to examine the state of water on the surface of $\mathrm{WO}_{3}$. As shown in Fig. 2, a continuous weight loss was observed from 50 to $280^{\circ} \mathrm{C}$. The weight loss was assigned to weakly adsorbed water on the surface of $\mathrm{WO}_{3}$. What is notable is the weight loss from 280 to $410^{\circ} \mathrm{C}$, which was recognized as strongly adsorbed water [17]. The existence of such water can greatly affect the gas sensing characteristic of the as-prepared $\mathrm{WO}_{3}$.

XPS spectra can provide information on the chemical states and relative quantities of surface elements. Fig. 3a shows the $W 4 \mathrm{f}$ core level of the as-prepared $\mathrm{WO}_{3}$ particles. It is a doublet, and the $\mathrm{W}$ $4 \mathrm{f}_{7 / 2}$ line at $36.1 \mathrm{eV}$ and the $\mathrm{W} 4 \mathrm{f}_{5 / 2}$ line at $38.3 \mathrm{eV}$ are associated with the $\mathrm{W}^{6+}$ oxidation state. The $\mathrm{O} 1 \mathrm{~s}$ peak in Fig. $3 \mathrm{~b}$ consists of three components. While the one at $530.78 \mathrm{eV}$ can be assigned to the oxygen covalently connected to $\mathrm{W}$, the one at $532.53 \mathrm{eV}$ corresponds to the oxygen species adsorbed on the $\mathrm{WO}_{3}$ surface. Unlike common results, a peak at $537.54 \mathrm{eV}$ was also observed, and it may be attributed to the existence of strongly bound surface water molecules, in accordance with the TGA results. Such water molecule is adsorbed on the surface of $\mathrm{WO}_{3}$ via coordination of its oxygen atom with Lewis acidic site, thus decreasing the electron density of the oxygen atom and making its electrons hard to ionize.

Fig. 4 shows the nitrogen adsorption-desorption isotherms of the as-prepared $\mathrm{WO}_{3}$. They are type II isotherms with sharp knees, and are different from those of mesostructured samples. The BET surface area of flower-like $\mathrm{WO}_{3}$ particles reaches as high as $48.1 \mathrm{~m}^{2} \mathrm{~g}^{-1}$, much higher than that of commercial $\mathrm{WO}_{3}$ $\left(\sim 9 \mathrm{~m}^{2} \mathrm{~g}^{-1}\right)$.

\subsection{Formation mechanism of flower-like $\mathrm{WO}_{3}$ particles}

SEM images of $\mathrm{WO}_{3}$ particles obtained via the same synthesis method but with varied periods of reaction time are shown in Fig. 5 in order to clarify the formation mechanism of flower-like $\mathrm{WO}_{3}$ particles. By considering Figs. $5 \mathrm{a}$ and $\mathrm{b}$ and $1 \mathrm{a}$, the formation of $\mathrm{WO}_{3}$ may be roughly divided into three stages. First, tungsten chloride hydrolyzed, and small tungsten oxide particles formed. It was a rapid process, and the formed tungsten oxide particles 

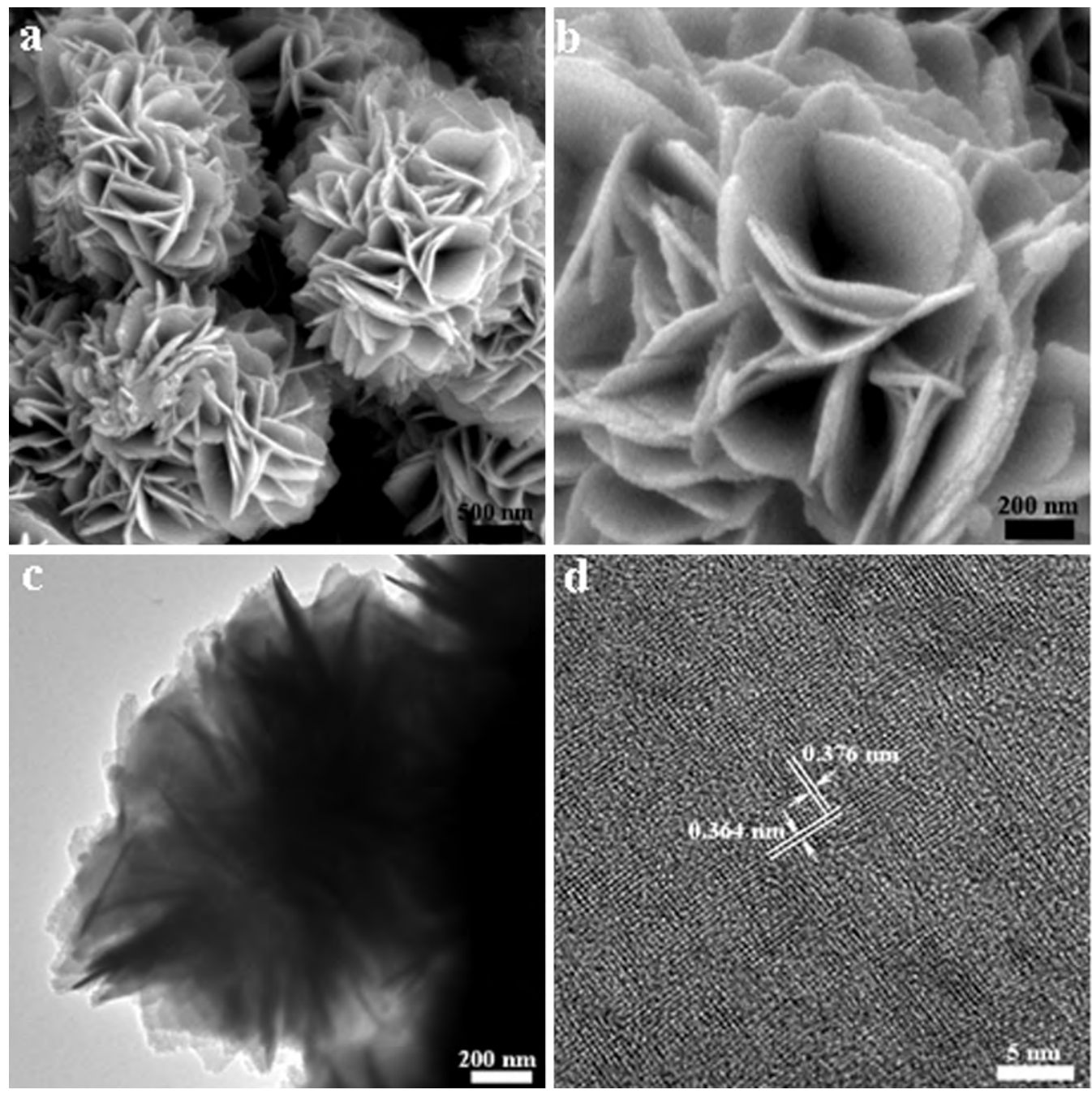

Fig. 1. (a) and (b) SEM images of flower-like $\mathrm{WO}_{3}$ particles at varied magnifications; (c) TEM image of a flower-like $\mathrm{WO}_{3}$ particle; (d) $\mathrm{HRTEM}$ image of a WO $\mathrm{W}_{3}$ flake.

were irregular. Second, tungsten oxide flakes began to grow simultaneously with consumption of the irregular particles. This stage took a long time and included changes of not only morphology but also crystal structure as discussed later. Eventually, when all the irregular particles were consumed, particles of well defined flower-like morphology formed. Corresponding XRD results indicated a simultaneous structural change with the morphological

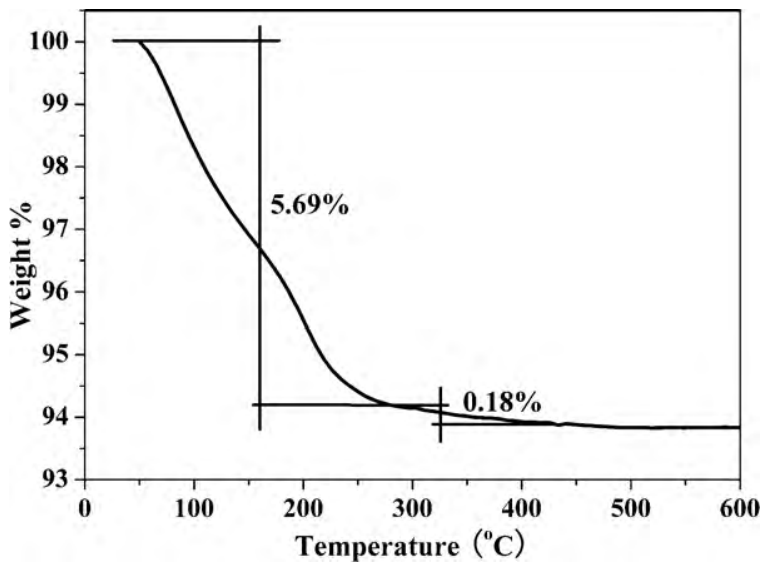

Fig. 2. TGA analysis of as-obtained $\mathrm{WO}_{3}$ particles. change. As can be seen in Fig. $6, \mathrm{WO}_{3}$ particles obtained after $24 \mathrm{~h}$ reaction showed typical orthorhombic crystal structure (JCPDS No. 20-1324). After reaction for $48 \mathrm{~h}$, though the main crystal structure was still orthorhombic, the peak intensity decreased and the peaks of monoclinic structure (JCPDS No 43-1035) appeared. After $72 \mathrm{~h}$ reaction, the crystal structure completely transformed to monoclinic when the flower morphology formed. These results indicate that the formation of the flower-like $\mathrm{WO}_{3}$ structure may adopt a re-growth procedure, i.e., the formed small tungsten oxide particles gradually re-grow in the specific directions of 200 and 020 , which are in accordance with the HRTEM results.

\subsection{Adsorption of DMMP on flower-like $\mathrm{WO}_{3}$ particles}

Understanding the interaction between targets and sensing material is important for developing highly effective sensors. The interpretation of DRIFTS spectral results has been considered an effective way to obtain the information of the interaction. The DRIFTS spectra of DMMP adsorption on flower-like $\mathrm{WO}_{3}$ particles are shown in Fig. 7. They can be broken up into two regions: the high-frequency region from 3200 to $2600 \mathrm{~cm}^{-1}$ that contains methyl stretching vibrations and the low-frequency region from 1800 to $700 \mathrm{~cm}^{-1}$ that contains $\mathrm{C}-\mathrm{O}, \mathrm{C}-\mathrm{P}$ and $\mathrm{P}=\mathrm{O}$ stretching vibrations and methyl deformation vibrations. The two regions can provide complementary information. 

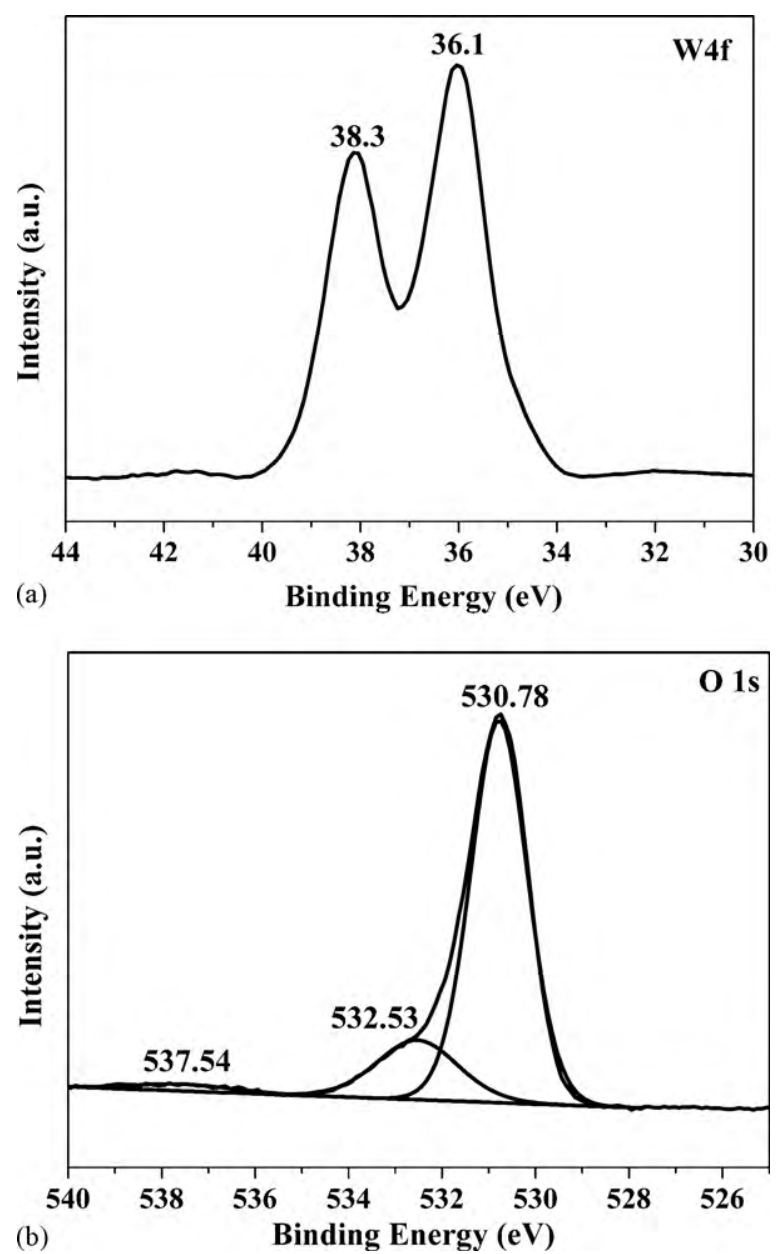

Fig. 3. XPS spectrum of as-obtained $\mathrm{WO}_{3}$ particles. (a) $\mathrm{W} 4 \mathrm{f}$ and (b) $\mathrm{O} 1 \mathrm{~s}$. The three curves are fitted.

In the high-frequency region, the methyl stretching modes can provide clear evidence if the decomposition reaction of DMMP occurres. However, as shown in the high-frequency region, the position of the methoxy group methyl stretching vibrations at 2956 and $2852 \mathrm{~cm}^{-1}$, and the position of phosphorus-bound methyl group at 2997 and $2923 \mathrm{~cm}^{-1}$, had no changes during the full time scale. This indicates that no decomposition but molecular

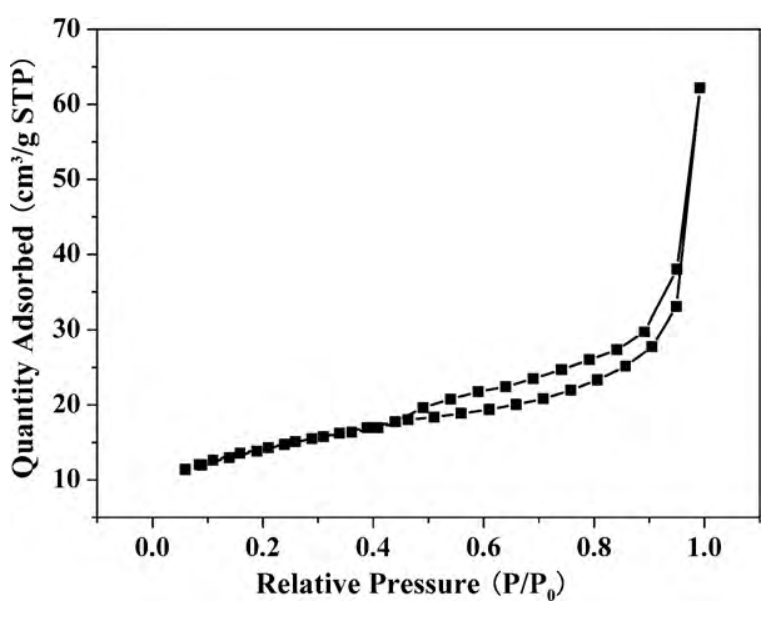

Fig. 4. Nitrogen adsorption-desorption isotherms of as-obtained $\mathrm{WO}_{3}$ particles.

adsorption occurred under such conditions. It is not hard to understand as the measurements were carried out at room temperature. However, the intensities of these bands clearly increased with, indicating a continuous adsorption of DMMP on flower-like $\mathrm{WO}_{3}$ particles.

Compared with the high-frequency spectral region, the lowfrequency spectral region is more complicated. The bands at 1464 and $1188 \mathrm{~cm}^{-1}$ (the methoxy methyl deformation modes) as well as those at 1419 and $1311 \mathrm{~cm}^{-1}$ (the phosphorus-bound methyl group deformation modes) underwent little change in position but clear increase in intensity, which again points to molecular adsorption in consistent with the results obtained in the high-frequency spectral region.

The frequency change of the $\mathrm{P}=\mathrm{O}$ stretching mode compared with gaseous DMMP can provide the nature of interaction between DMMP and $\mathrm{WO}_{3}$. As observed in the low-frequency spectral region, the frequency of $\mathrm{P}=\mathrm{O}$ stretching mode, which occurs at $1276 \mathrm{~cm}^{-1}$ in gaseous phase, shifted to 1231 and $1253 \mathrm{~cm}^{-1}$ upon adsorption within the first minute, 45 and $23 \mathrm{~cm}^{-1}$ lower than those of gaseous DMMP. According to previous reports [17-19], the two positions are the evidence of the formation of two types of bonding between $\mathrm{P}=\mathrm{O}$ and $\mathrm{WO}_{3}$ surface sites: adsorption via hydrogen bonding $\left(1231 \mathrm{~cm}^{-1}\right)$ and with surface Brønsted sites $\left(1253 \mathrm{~cm}^{-1}\right)$. Although a third adsorption mode (Lewis acid site adsorption) existed, as reported before [18,19], no evidence was observed in
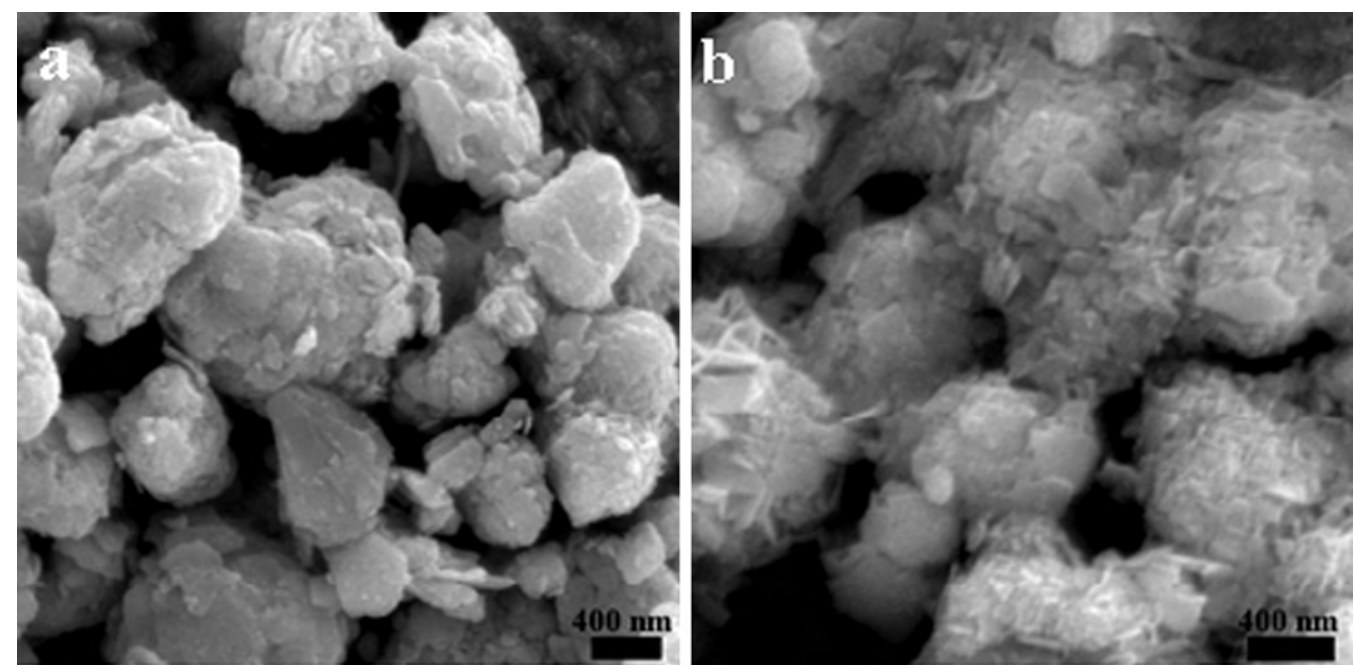

Fig. 5. SEM images of $\mathrm{WO}_{3}$ particles obtained using varied periods of reaction time: (a) $24 \mathrm{~h}$; (b) $48 \mathrm{~h}$. 


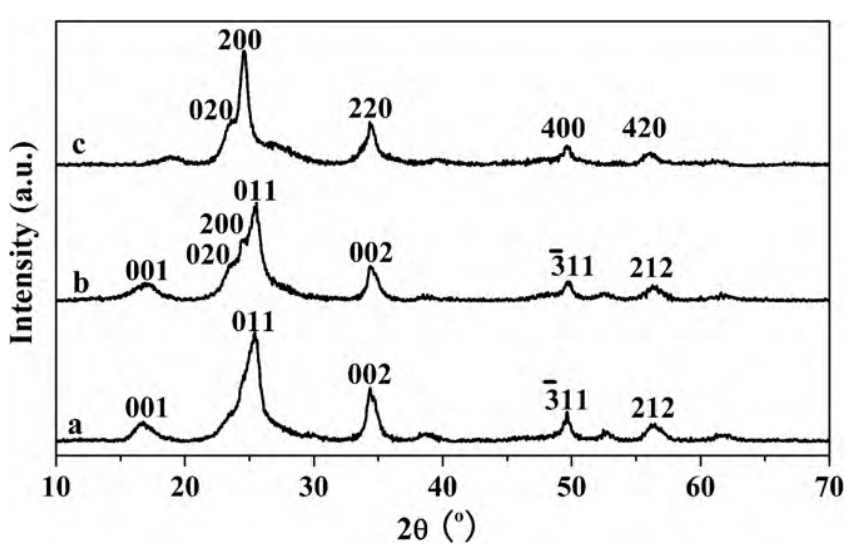

Fig. 6. XRD patterns of the $W_{3}$ with varied reaction times. (a) $24 \mathrm{~h}$; (b) $48 \mathrm{~h}$; (c) $72 \mathrm{~h}$.

the current experiment. It can be easily understood if we consider that the adsorption herein occurred at room temperature rather than at higher temperature as in the previous reports. With increasing time, the peak at $1253 \mathrm{~cm}^{-1}$, increases in intensity quickly and overlaps with the peak at $1231 \mathrm{~cm}^{-1}$ after only $5 \mathrm{~min}$. At the full time scale, no position shift is observed, indicating no other interaction or reaction happened. Thus, it could be concluded that the adsorption of DMMP on $\mathrm{WO}_{3}$ surface occurred via hydrogen bond and with surface Brønsted sites, and the later played a predominant role for the adsorption. The results gained by DRIFTS are quite different from those reported in previous papers, in which
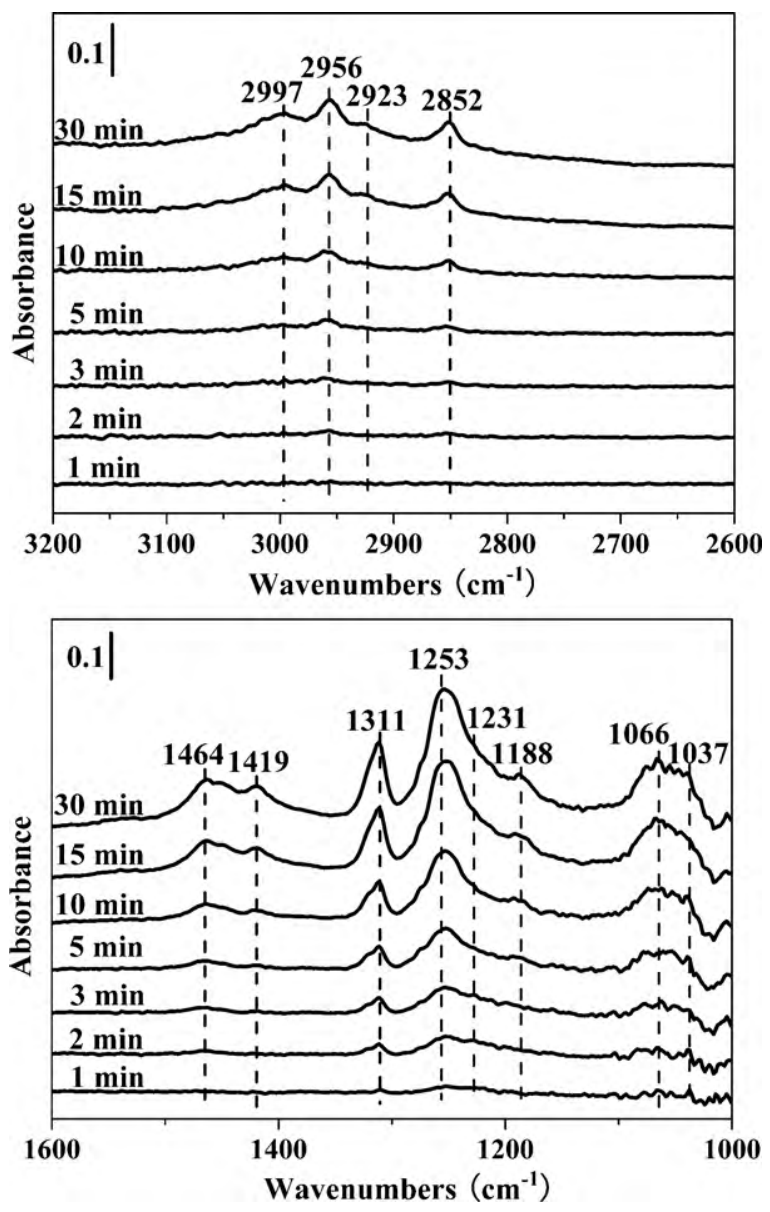

Fig. 7. DRIFTS spectra of DMMP on $\mathrm{WO}_{3}$ particles at different times.

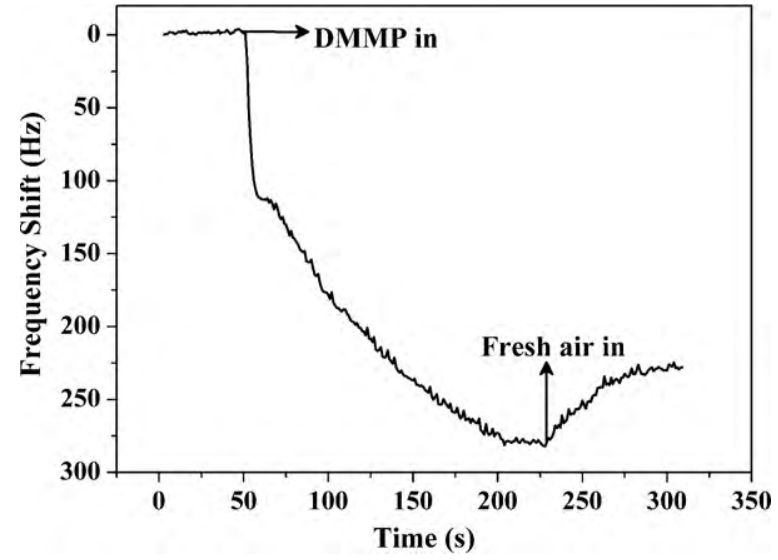

Fig. 8. Response profile of $\mathrm{WO}_{3}$ functionalized QCM resonators to DMMP at $10^{\circ} \mathrm{C}$. The DMMP concentration was $4 \mathrm{ppm}$.

the adsorption of DMMP mainly occurs via hydrogen bonding at room temperature [14] or on Lewis acid sites at higher temperatures. However, in the current work, the adsorption took place mainly at Brønsted sites. The different adsorption modes may be caused by the different synthetic methods and would in turn result in different gas sensing properties which will be discussed later.

\subsection{Gas sensing properties}

Fig. 8 shows a typical gas sensing response of flower-like $\mathrm{WO}_{3}$ particles functionalized QCM resonator to DMMP. Once DMMP was introduced, the frequency decreased (by $113 \mathrm{~Hz}$ ) quickly in the first $8 \mathrm{~s}$. The shift was caused by the adsorption of DMMP on the outer surface of the flower-like $\mathrm{WO}_{3}$ particle. Then, a continuous but slow decrease occurred and it lasted for $145 \mathrm{~s}$ until a steady state was reached. The corresponding frequency shift was $168 \mathrm{~Hz}$. The relative long time might be attributed to slow diffusive access of DMMP to the inner surface of flower-like $\mathrm{WO}_{3}$ particles, as all the tests were carried out at atmospheric pressure. When switched to fresh air, the frequency began to increase, and could partially recover during the test. The incomplete recovery was probably due to the relatively strong interaction between DMMP and surface Brønsted sites. The word "relatively" used here is based on the fact that though it is hard for DMMP to desorb from Brønsted sites under experimental conditions, the resonator could fully recover by putting it in vacuum for $2 \mathrm{~h}$. The response time, which is defined as the period from introduction of DMMP to the time when the sensor reaches its steady state, was $153 \mathrm{~s}$. The sensitivity, the ratio of maximum frequency shift $(281 \mathrm{~Hz})$ to DMMP concentration ( $4 \mathrm{ppm}$ ), reached as high as $70 \mathrm{~Hz} / \mathrm{ppm}$. For comparison, previously reported $\mathrm{WO}_{3}$ nanoflakes with a relatively low surface area $\left(10.2 \mathrm{~m}^{2} / \mathrm{g}\right)$, was tested under identical experimental conductions. As illustrated in Fig. 9, at varied temperatures, flower-like $\mathrm{WO}_{3}$ particles had sensitivity more than twice of that of $\mathrm{WO}_{3}$ nanoflakes. The enhanced sensitivity should be mainly attributed to the high specific surface area of flowerlike $\mathrm{WO}_{3}$ particles. However, though the flower-like morphology could bring about high sensitivity, the response time (154s) was much longer than that of nanoflakes (30 s). The extended response time could be attributed to slow diffusive access of DMMP to the inner surface of flower-like $\mathrm{WO}_{3}$ particles. The comparative studies indicated that not only the components but the morphology and surface area could have important effects on gas sensing behavior.

Interfering agents such as water, methanol, etc, may influence the sensitivity of the sensors. Thus, gas sensing tests to DMMP in 


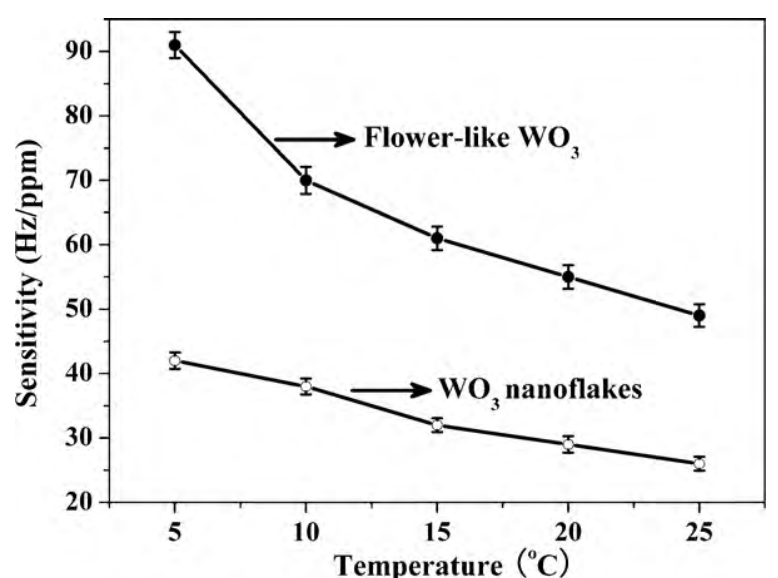

Fig. 9. Plots of sensitivity versus temperature. DMMP concentration was $4 \mathrm{ppm}$, and $\mathrm{WO}_{3}$ coating amount was $16.2 \mu \mathrm{g}$.

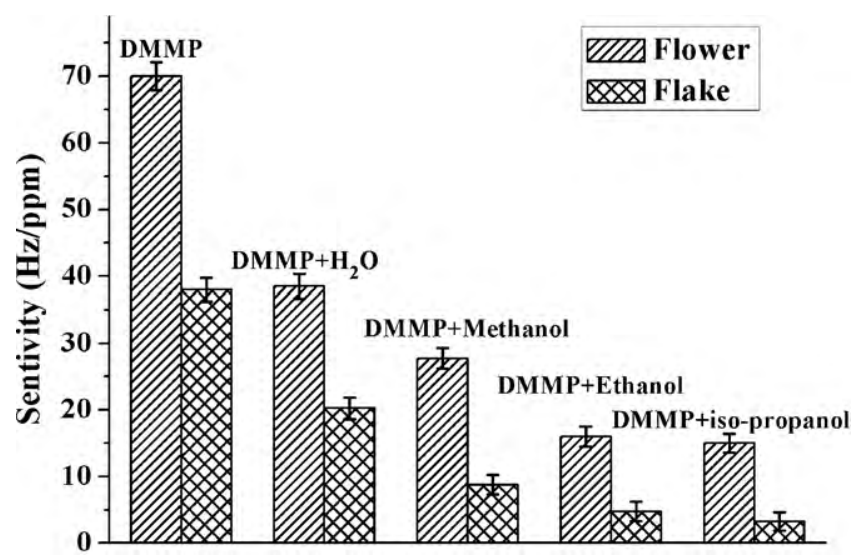

Fig. 10. Cross-sensitivities of flower-like $\mathrm{WO}_{3}$ and $\mathrm{WO}_{3}$ nanoflake functionalized QCM resonators at $10^{\circ} \mathrm{C}$. DMMP concentration was $4 \mathrm{ppm}$, and those of interfering agents were normalized to $10,000 \mathrm{ppm}$.

presence of interfering agents were conducted in order to access the cross-sensitivity of flower-like $\mathrm{WO}_{3}$ functionalized QCM resonator. For comparison, $\mathrm{WO}_{3}$ nanoflake functionalized $\mathrm{QCM}$ resonator was also tested. As shown in Fig. 10, the presence of interfering agents significantly reduced the sensitivity of both sensors, which may be explained by competitive adsorption of interfering agents with DMMP on $\mathrm{WO}_{3}$. In spite of the existence of excess interfering agents, however, the flower-like $\mathrm{WO}_{3}$ functionalized resonator still showed sound sensitivity to DMMP. In contrast, the sensitivity of $\mathrm{WO}_{3}$ nanoflake functionalized resonator became quite low. These cross-sensitivity results indicated the importance of high sensitivity to sensing materials. High sensitivity cannot only make sensing materials highly sensitive to targeted gases even at their low concentrations, but also provide sound sensitivity in present of interfering agents.

\section{Conclusions}

Flower-like $\mathrm{WO}_{3}$ particles with high specific surface area was synthesized without surfactant/template assistance. Comparative studies indicate that higher specific surface areas can lead to higher sensitivity, while the morphology results in relative long response time. The enhanced sensitivity of flower-like $\mathrm{WO}_{3}$ functionalized QCM resonator showed higher cross-sensitivity in presence of interfering agents than $\mathrm{WO}_{3}$ nanoflake functionalized QCM resonator, which is a great improvement for $\mathrm{WO}_{3}$ functionalized QCM resonators. DRIFTS results revealed the nature of DMMP adsorption on the surface of $\mathrm{WO}_{3}$. Although the adsorption occurs via hydrogen bond and on Brønsted sites at the initial time, the latter plays a predominant role.

The key points of this work involves not only a new way for surfactant/template free synthesis of flower-like $\mathrm{WO}_{3}$ particles with high specific surface area, but also a deep understanding the effect of morphology and specific surface area on sensing behaviors. The results may provide useful information for the development of gas sensors for practical application.

\section{Acknowledgements}

This work was supported by the Knowledge Innovation Program of the Chinese Academy of Sciences (CAS) (Grant No. KGCX2-YW111-5), the National Natural Science Foundation of China-NSAF (Grant No. 10776034), and the National Natural Science Foundation of China (Grant No. 20871118), and "Hundred Talents Program" of CAS.

\section{References}

[1] S.G. Kwon, T. Hyeon, Acc. Chem. Res. 41 (2008) 1696-1709.

[2] G. Shen, P.C. Chen, K. Ryu, C. Zhou, J. Mater. Chem. 19 (2009) 828-839.

[3] Y. Jun, J. Choi, J. Cheon, Angew. Chem. Int. Ed. 45 (2006) 3414-3439.

[4] K. Tuovinen, Toxicology 196 (2004) 31-39.

[5] T.J. Dale, J. Rebek Jr., Angew. Chem. 121 (2009) 7990-7992.

[6] K.J. Wallace, R.I. Fagbemi, F.J. Folmer-Andersen, J. Morey, V.M. Lynth, E.V. Anslyn, Chem. Commun. (2006) 3886-3888

[7] J.M. Rathfon, Z.M. Al-Badri, R. Shunmugam, S.M. Berry, S. Pabba, R.S. Keynton, R.W. Cohn, G.N. Tew, Adv. Funct. Mater. 19 (2009) 689-695.

[8] G. Liu, J. Wang, R. Barry, C. Petersen, C. Timchalk, P.L. Gassman, Y. Lin, Chem. Eur. J. 14 (2008) 9951-9959.

[9] J.W. Grate, Chem. Rev. 108 (2008) 726-745.

[10] R.P. Manginell, D.R. Adkins, M.W. Moorman, R. Hadizadeh, D. Copic, D.A. Porter, J.M. Anderson, V.M. Hietala, J.R. Bryan, D.R. Wheeler, K.B. Pfeifer, A. Rumpf, J. Microelectromech. Syst. 17 (2008) 1396-1407.

[11] P.R. Lewis, R.P. Manginell, D.R. Adkins, R.J. Kottenstette, D.R. Wheeler, S.S. Sokolowski, D.E. Trudell, J.E. Byrnes, M. Okandan, J.M. Bauer, R.G. Manley, G.C. Frye-Mason, IEEE Sens. J. 6 (2006) 784-795.

[12] Y. Sun, Y. Xia, Science 298 (2002) 2176.

[13] X. Wang, J. Zhuang, Q. Peng, Y. Li, Nature 437 (2005) 121.

[14] Y. Zhao, J. He, M. Yang, S. Gao, G. Zuo, C. Yan, Z. Cheng, Anal. Chim. Acta 654 (2009) 120-126.

[15] J. Lu, K.M. Kosuda, R.P. Van Duyne, P.C. Stair, J. Phys. Chem. C 113 (2009) 12412-12418.

[16] S.M. Kanan, Z. Lu, J.K. Cox, G. Bernhardt, C.P. Tripp, Langmuir 18 (2002) 1707-1712.

[17] S.M. Kanan, Z. Lu, C.P. Tripp, Curr. Opin. Solid State Mater. 11 (2007) 19-27.

[18] C.S. Kim, R.J. Lad, C.P. Tripp, Sens. Actuators B 76 (2001) 442-448.

[19] S.M. Kanan, Z. Lu, C.P. Tripp, J. Phys. Chem. B 106 (2002) 9576-9580. 